\title{
¿Moral provinciana o ética global?
}

\author{
"En lo referente a toda la \\ cháchara moral de unos sobre otros \\ ha llegado la hora del asco".
}

F. Nietzsche
Las expectativas surgidas a partir de la aparición del documento Bases para el plan de nación (San Salvador, 16 de enero de 1998), elaborado por la Comisión Nacional de Desarrollo, son a todas luces positivas, siempre y cuando no se queden ancladas en la alabanza irresponsable o en la crítica estéril. Especialmente nos preocupa el primer caso, no porque ocupe más espacio en los medios de difusión, ni por su eficacia para volver inútil el potencial crítico-transformador, sino porque obedece a la lógica interna del planteamiento que se nos hace, o sea, está contenido en el documento el que se le asuma de modo acrítico, haciendo abstracción de realidades o de posturas ideológicas. Implícitamente, las Bases para el plan de nación se proponen a sí mismas como "desideologizadas", con lo cual se envía un mensaje claramente dogmático a todo aquel que asuma, consciente o no, una determinada ideología: ¡manténgase al margen! Es así que quienes nos ocupamos de lo ético nos encontramos ante unos planteamientos valorativos que pretenden ser naturales, deducibles de los meros "hechos", lo cual, independientemente de los mismos y lo que puedan significar, son cuestionables por el hecho de ser presentados como naturales.

El documento es rico en conceptos que competen a la ética; los valores, la moral, el deber son algunos de los tópicos de los que se habla constantemente, incluso se les dedica en exclusiva algu- nos párrafos. El problema estriba en que, nos parece, no se puede hacer una consciente y responsable reflexión sobre los valores si de entrada se ciera la posibilidad de hacer planteamientos que tengan su origen en un marco ideológico diferente o, más bien, que simplemente presupongan la existencia de una ideología. Al leer las Bases para un plan de nación nos encontramos con un enfoque moralizante, en cuanto lo ético es entendido como propuesta de unos valores, sin tomarse la molestia de averiguar o discutir siquiera si éstos son válidos o no. El que los contenidos de estos planteamientos sean de marcado talante conservador y provinciano viene a ser un problema ulterior, ya que si hubiera alguna objeción frente a ellos ésta no serviría de nada al encontrarse con el argumento de presunta naturalidad de los mismos.

El lector acucioso notará inmediatamente la mutua imbricación existente entre los dos problemas planteados: es probable que las mentalidades conservadoras se opongan sin más a la labor críti$\mathrm{ca}$, es probable que haya mucho de dogmatismo en el talante conservador y es posible que la referencia a los "valores" sea un recurso conservador. Pero no es en tal tipo de supuestos en los que hemos de basarnos sino en el hecho constatable de un planteamiento ideológico que combina - Laleatoriamente?- dogmatismo y conservadurismo justo en el campo de la ética. Por lo tanto, quisiéramos emprender una crítica de la letra y el espiri- 
tu del mismo que no aísle nuestros dos problemas, pero que tampoco termine por identificarlos -que no son lo mismo.

En cuanto al primer problema, recurriremos al lenguaje cotidiano apuntando que hoy en día uno de los insultos más eficaces se expresa con palabras como "ideologizado", "ideológico", etc. El derrumbe del socialismo real nos trajo toda clase de extravagancias, entre las cuales encontramos las aseveraciones que sostienen la "inviabilidad" de las ideologías, la infructuosidad de lo ideológico frente a lo científico-natural. De hecho, siguiendo a Franz Hinkelammert, la apología del sistema capitalista en su versión más actual, el neoliberalismo o capitalismo cínico, sostiene como elemento justificador su correspondencia inequívoca con "hechos" más que con conceptos. Se recurre al "cálculo de utilidad" como eje del comportamiento no sólo económico sino humano en general y, cuando la realidad contradice esto, no se corre hacia la defensa del "bien común", por sospecha de ideológico, sino que se recurre al "hecho" de la "guerra económica", entendida como "competencia natural por los bienes", de tal forma que no quede duda del carácter científico de lo que se afirma. Por supuesto que decir aquí científico equivale a decir "no-ideológico".

El documento que nos ocupa no es la excepción, ya que pretende cierto carácter de ascepcia ideológica al ubicar los contenidos y la metodología presentados como fruto del consenso y el pluralismo (?) y al afirmarse explícita e implícitamente la no adscripción del mismo a ningún "esquematismo de las visiones ideologizadas" (p. 11). En este sentido son interesantes los planteamientos de Ignacio Ellacuría sobre la diferencia entre ideología c idcologización, planteados en su artículo "Función liberadora de la filosofía": "Aun siendo la ideología un fenómeno ambiguo, es, por lo pronto, algo necesario y, además, algo muy importante en la determinación de la vida social, de la vida comunitaria y de la vida personal"'. Lo ante- rior no quiere decir que no exista un sentido negativo de ideología: "Evidentemente, hay un sentido peyorativo de la ideología entendida como función encubridora de la realidad social, pero aun en ese sentido peyorativo se muestra la importancia y la connaturalidad de lo ideológico"3. Más adelante vuelve a presentar la ideología rescatando sus diversas funciones positivas, entre las cuales nos interesa especialmente la de explicación valorizadora: "Y es que hay un sentido no peyorativo y necesario de las ideologías, si entendemos por tales una explicación coherente, totalizadora y valorizadora, sea por medio de conceptos, de símbolos, de imágenes, de referencias, etc., que va más allá de la pura valoración fragmentada, tanto de campos limitados como, sobre todo, de campos más generales y aun totales. Con esto queremos decir que la ideología no sólo juega un papel sustitutivo y/o meramente propedéutico para lo que fuera un pensamiento no ideológico y/o científico, sino que, en alguna medida, siempre está presente y siempre es efectiva, no sólo para aquellos que no han alcanzado ese nivel científico, y que, desde luego, es la mayoría de la humanidad, al menos respecto de una inmensa gama de aspectos profundamente humanos, sino también para aquellos que se dicen científicos en lo que respecta a su propio campo científico"4. Pero esto no debe significar el que se olvide los problemas que puede causar cierla función peyorativa de las ideologías, sólo que en este lugar Ellacuría distingue entre ideología e ideologización: "No obstante, es innegable que se da un factor de ideologización en las ideologías (...) La ideologización añade a la ideología el que inconsciente $\mathrm{c}$ indeliberadamente se expresen visiones de la realidad, que lejos de manifestarla, la esconden y deforman con apariencia de verdad, en razón de intereses que resultan de la conformación de clases o grupos sociales y, o étnicos, políticos. religiosos, etc." ${ }^{\mathrm{s}}$

Pero bien, ¿en qué afecta esto al problema del carácter crítico? Pues, sencillamente y como ya lo

1. Cir. de Hinkelammert, F. "El capitalismo cínico y su crítica: La crítica de la ideología y la crítica del nihilismo" y "Asesinato es suicidio: de la utilidad de la limitación del cálculo de utilidad", escritos inéditos correspondientes a dos cursos impartidos en la UCA en 1997.

2. Ellacuría, I. "Función liberadora de la filosofía", en Veinte años de historia en El Salvador (1969-1989). Escritos políticos, vol. I, San Salvador, 1993, p. 96. El artículo fue publicado originalmente en ECA, No 435-436, 1985, pp. 45-64.

3. Ibid.

4. Ibid., p. 98.

5. Ibid., pp. 98-99. 
adelantábamos antes, en que al renunciarse explícila o implícitamente a la ideología, los planteamientos asumen el carácter de "naturales", con lo cual la crílica queda sin justilicación alguna o, en todo caso, se circunscribe a un ámbito especílico, a unos límites determinados. Lo que resulta de esto es un lipo de análisis social, económico y político que se enfoca únicamente sobre los objetivos por conseguir, pero se cuida bien de tres puntos: el pasado, las dificultades y los protagonistas. ¿Acaso no hay una introducción histórica en el documento, así como una referencia constante a nuestro pasado? Sí la hay, pero nuestra observación apunta al hecho concreto de que se resta importancia a lo que hay en el pasado capaz de turbar nuestro optimismo; pensemos, por ejemplo, en los acuerdos de paz incumplidos o cumplidos a medias; en la alergia que causa en algunos el recuerdo de los márlires; ya no se diga aquel famoso monumento a las víctimas de la guerra que nunca sc construyó. El pasado tiene también lecciones importantes que no se reducen al planteamiento simplista de los crrores cometidos y a la identificación maniquea de la paz con la concordia y la guerra con el odio. No debemos olvidar que las causas de la guerra las encontramos principalmente en la marginación económica ejercida por grupos de poder económico; no debemos olvidar además que fue la tan odiada gucra la que propició los avances en el ejercicio de la democracia y las garantías para las libertades civiles. Difícilmente obtendremos un buen futuro a fuerza de la no deducción de responsabilidades y el decreto constante de amnistías c indultos, tal como sucede en un documento en el que no encontramos ningún nomhre propio - excepto, claro está, el de los autores. Si las ideologías han muerto no se hace necesario saber cuáles propiciaron qué o quiénes causaron dónde. Hoy sólo nos queda la razón científica -léase tecnologismo- y a ella hay que arrimarse.

$\mathrm{Y}$ bien, nuestro avispado interlocutor nos podrá decir entonces: $i$ acaso se han planteado estos puntos de vista para la discusión? ¿No será que la acusación de dogmatismo es excesiva? ¿Acaso los autores no han enfatizado el que se trata sólo de unas "bases" y no de planteamientos acabados y excluyentes? Complacidos por las observaciones responderemos que de ninguna forma es excesivo el trato dado al documento, pues, si bien es cierto que lo que tenemos son ideas para la discusión, el talante crítico queda excluido de la misma por definición, ya yue toda observación que se salga de los límites impuestos por el análisis "pluralista" -léase ideológico- de sus autores se excluye a sí misma del debate. El problema no es si se deja espacio para la crítica, lo cual se nos respondería de inmediato afirmativamente, sino si es posible hacer la crítica sobre un asunto tan fundamental como el hacia dónde dirigirnos en tanto nación sin recurrir a la ideología. Es dilícil imaginar una discusión sobre las políticas por seguir en una organización empresarial u organismo del estado sin una valoración de las mismas, y sería muy irresponsable el dejar semejante tarea a quienes no poseen "una explicación coherente, totalizadora y valorizadora" de la realidad de la organización en cuestión, ya no se diga si tal discusión se reliere más bien a la sociedad salvadoreña.

Podría objetársenos tambićn que quizás no hemos reparado en que los autores del documento ya tienen bien claro la diferencia entre ideología c ideologización, dado que se utiliza claramente y en sentido peyorativo este último término (Cfr. p. 11) y, por lo tanto, nuestras observaciones no tienen sentido. Ante esto diremos, en primer lugar, que nuestras observaciones no se refieren a enun-

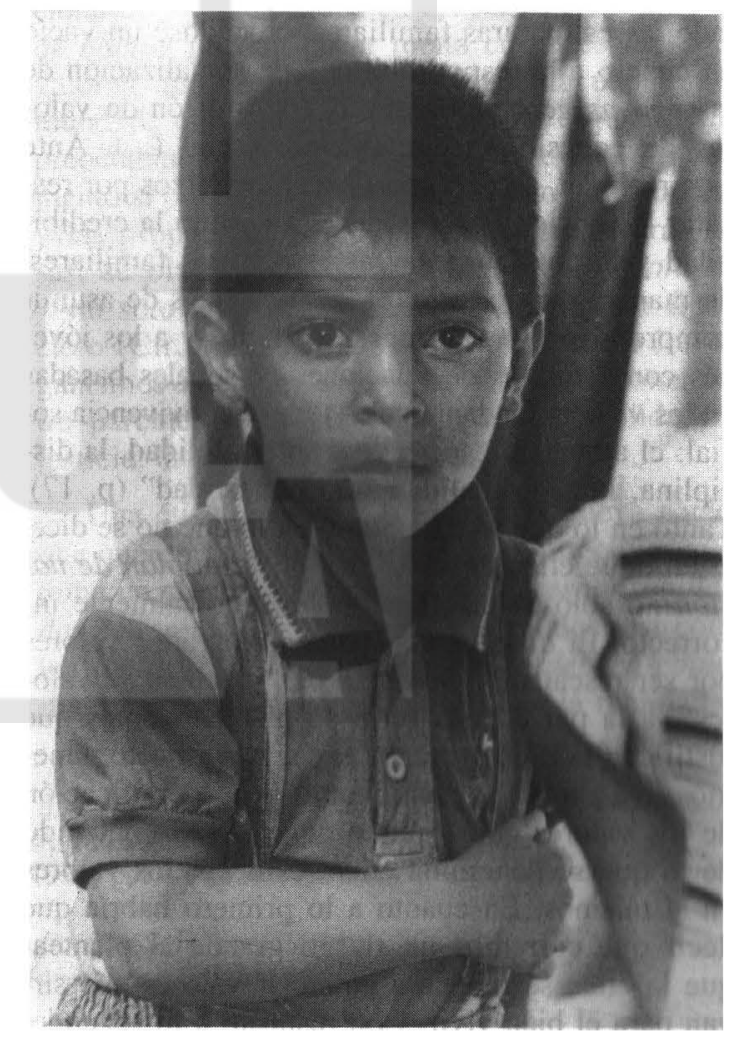


ciados explícitos en contra de la ideología o de la ideologización, de hecho el problema que vemos es el talante global del documento, pretendidamente fruto del consenso y cargado de valorizaciones que se pretenden hacer pasar por "objetivas" y "desideologizadas", pero que se obtienen de un análisis de la realidad salvadoreña en el que no tenemos ni sujetos ni deducción de responsabilidades, aunque sí, como veremos adelante, una postura ideológica determinada. En todo caso, en segundo lugar, nos parece que los autores de las Bases para un plan de nación sí identifican los términos, dado su no reconocimiento, explícito o implícito, de lo positivo que podemos encontrar en la ideología. Enseguida veremos que el asunto se torna más preocupante al introducirnos directamente en las argumentaciones en torno a la ética.

En el documento se apuesta por "una sociedad con firmes estructuras familiares, interactuando a partir de valores fundamentales para la convivencia social pacífica" (p. 17), identificándose inmediatamente los peligros para la misma: "La cultura machista, la irresponsabilidad en la procreación, la falta de educación, la pobreza y, más recientemente, el conflicto armado y la emigración, han afectado las estructuras familiares, creándose un vacío en cuanto a la responsabilidad de socialización de las nuevas generaciones y la transmisión de valores de cohesión y convivencia social (...). Ante esta realidad, es necesario hacer esfuerzos por rescatar la función de la familia, así como la credibilidad y la confianza en las estructuras familiares, de manera que los adultos sean capaces de asumir compromisos para formar a los niños y a los jóvenes con ejemplos de relaciones personales basadas en los valores fundamentales para la convivencia social: el amor, el respeto, la responsabilidad, la disciplina, la espiritualidad y la honestidad" (p. 17). Tanto en lo que se dice como en lo que no se dice, el enfoque ético en las Bases para un plan de nación no sólo es insuficiente sino radicalmente incorrecto. El documento menciona algunos valores por ser rescatados. Se habla de "vigencia de valores", a la par de una serie de planteamientos que justifican la preocupación ética. Al respecto, tenemos una duda seria en cuanto a la identificación de los valores con lo ético como en el contenido de lo que se denomina ético, es decir, los valores en sí mismos. En cuanto a lo primero habría que decir que corremos un riesgo grande al plantear que la ética se reduce a enunciar valores que sirvan para el bien vivir. Con respecto a lo segundo, es cuestionable si habrá algo que rescatar o si, más bien, habrá que replantear unos valores acordes a los tiempos actuales; aun en el caso de un rescate de valores se plantea el espinoso asunto de qué es lo que se rescata y qué es mejor dejar en el olvido. Ahora bien, en ambas situaciones necesitaremos de una fundamentación de criterios de comportamiento que nos den luces, o sea, necesitaremos de una ética para luego establecer una moral.

La fundamentación ética se convierte en elemento ineludible si queremos justificar razonablemente nuestro comportamiento. Asimismo es importante que los valores que nos parecen esenciales tengan un fundamento claro y comprensible para todos, de tal forma que el consenso sobre los mismos sea posible. De otro modo caemos en el peligro de un dogmatismo ético que podría acarrear más rechazo que aceptación. Veamos lo que dice el documento: "Vigencia de valores. Construir una sociedad solidaria, con estabilidad social y económica, y cohesionada hacia objetivos comunes de desarrollo, tiene como condición el rescate, fortalecimiento y equilibrio de valores de manera que éstos adquieran plena vigencia en las relaciones interpersonales, así como en la vida y en la misma estructura de la sociedad. Hay que vivir la solidaridad, la libertad, la responsabilidad, la justicia, la seguridad y la honradez. La promoción de valores a través del sistema educativo requiere que los agentes responsables del mismo - principalmente educadores, padres de familia y medios de comunicación - se compenetren del desafío que plantea generar actitudes y hábitos acordes con la vigencia de dichos valores" (p. 25). Percibimos a las claras que los valores que se nos proponen en el documento adolecen no sólo de falta de una mínima justificación sino, además, de un cierto conservadurismo - iideología!- más o menos franco desde el momento en que se coloca a la integración familiar como el punto de arranque en su planteamiento (Cfr. p. 17).

La moral tradicional (en tanto se propone sin ambages un "rescate" de valores de raigambre familiar, comunitaria y religiosa), integrista (por la ortodoxia y actitud hostil ante cualquier tipo de revisión razonable) y naturalista (ya porque los "hechos" determinan los deberes, ya por fundamentarse en una determinada "metafísica") se plantea como buena en sí misma, a priori, mientras las señales que se nos envían desde la vida misma de la gente indican más bien unos estilos 
de vida, unas formas de vivir las relaciones interpersonales y sociales, en fin, un ethos que exige valores nuevos que nos permitan enfrentar secularmente y en clave global nuestra realidad. Las uniones libres, los divorcios y los jóvenes que han hecho de la "mara" su familia, nos interpelan actualmente con sus nuevas formas de convivencia, con lo cual cuestionan seriamente la concepción tradicional del núcleo familiar —matriarcal o patriarcal- como "base de la sociedad". Y esto es así porque vivimos en una época a la que llamamos postmodernidad justamente porque los valores fundamentales de la modernidad son puestos en cuestión, no sólo por los filósofos y demás intelectuales, sino, y esto no es menos importante, por la praxis misma de los hombres del siglo veinte. Observando esta praxis, acercándonos a la vida de los pueblos, nos encontramos con el hombre postmoderno, el cual encarnaría lo que, según Nietzsche, es un carácter fundamental del nihilismo: "los valores supremos pierden validez". El filósofo italiano Vattimo profundiza en esto al sostener que somos hombres sin verdad ni fundamento; lo que está en tela de juicio no es sólo éste o aquel fundamento, sino el que haya algún fundamento y, aún más, el que debamos dedicarnos a buscarlo ${ }^{7}$. Esto significa - para nuestra preocupación-que la ética necesita primero replantearse a sí misma en sus fundamentos para luego delimitar los valores que digan algo en nuestro mundo. Anteriormente propusimos unos criterios a tomar en cuenta a la hora de fundamentar la ética: secularidad y globalidad. Esto exige algunas explicaciones.

Secular debe ser la ética en tanto tome en cuenta al "siglo", o sea, las condiciones prácticas de la realidad mundana en sus precisas determinaciones temporales. En este sentido, "mundano" no es peyorativo, ni debe ser entendido, como hacen algunos, como lo opuesto a "sagrado". Sencillamente planteamos que es necesario atenerse en la fundamentación ética a las condiciones reales y prácticas de la vida de los hombres, los sujetos éticos, sin recurrir apriorísticamente a principios eternos e inmutables, los cuales, con sus pretensiones de universalidad y absolutez, son proclives al dogmatismo ${ }^{8}$.

Por otro lado, es importante el planteamiento de que los problemas que son más graves tienen su raíz en determinaciones globales, lo cual exige una ética global. En este sentido, son interesantes las observaciones de Erwin Silva al respecto: "No hay supervivencia sin una ética mundial (...) Es necesario un nuevo talante ético global porque, en realidad, problemas como la catástrofe ecológica, el hambre, la guerra, el terrorismo, las pandemias, son problemas universales que requieren una aplicación de principios éticos globales"'. La realidad de la globalización implica problemas fundamentales que son compartidos por la humanidad y se encuentran mundialmente interdeterminados. Por otra parte, la búsqueda de valores que nos ayuden a enfrentar esta realidad global no puede eludir el que el poder hegemónico dentro de la misma haya creado su propio sistema de valores fundamentado en "la religión del mercantilismo (...) La ética que sustenta esta religión mercantilista... es competitiva y sustituye a la ética del compartir"10. Nos parece difícil que aquellos valores provincianos - "nacionales"- planteados en las Bases para un plan de nación puedan hacer mella en un esquema de valores que se apoya en el sistema económico mundial, radicalmente insolidario e injusto. Más preocupante es lo incoherente que resulta el documento si ponemos estos valores junto a los análisis y las propuestas económicas que, entre otras cosas, se olvidan de lo insolidaria de las políticas —no sólo las "tecnologías" - del sistema financiero (Cfr. p. 30-31) y de las presiones de los organismos internacionales que obligan a poner entre paréntesis "la libertad, la responsabilidad, la justicia, la seguridad y la honradez".

Una ética y unos valores para la nueva nación que queremos sólo serán realistas y efectivos si se toma en cuenta a los sujetos y las responsabilidades concretas, con nombres y apellidos, así como los limites a la libertad en que se deberá coincidir. Esto implica leer en clave ética la realidad de

\footnotetext{
6. Nietzsche, F. Voluntad de poderío, Madrid, 1981, p. 33.I. Fr.1., cita de E. Silva, "Etica, postmodernidad y globalización", en A.A.V.V., Mundialización y liberación, Managua, 1996, p. 210.

7. Cfr. Vattimo, G. El fin de la modernidad, Barcelona, 1990, pp. 47-48, en A.A.V.V., Mundialización y liberación, op. cit., p. 210.

8. Cfr. González, A. Introducción a la práctica de la filosofía, San Salvador, 1991, pp. 306-312.

9. Silva, E. "Etica, postmodernidad y globalización", en Mundialización y liberación, op, cit, p. 211.

10. lbid.
} 
la globalización y las políticas económicas, las cuales son determinadas mundialmente por las potencias económicas transnacionales, las naciones ricas y los organismos internacionales con la complicidad de las burguesías domésticas. No es ignorando las condiciones de desigualdad y marginación -ieconómicas!-, las cuales tienen actualmente una radicación en la estructuración del sistenia económico global, que se hará efectivo el diálogo. El sistema mundial actual exige para su funcionamiento el que haya unos excluidos; por lo tanto, un planteamiento ético que se limite a un "rescate" de valores a espaldas de la valoración capitalista neoliberal es ingenuo o malintencionado. Ante esto es elocuente la afirmación de Jordi Corominas: "Se moralizan exhaustivamente las acciones más irrelevantes y ni siquiera se perciben las más aplastantes"'!.

Y es que el lérmino "global" implica en este lugar mucho más que el comprender que los vínculos planetarios exigen fundamentos éticos y valores mundiales: es necesario entender que toda la praxis humana es ética; todas las instituciones sociales, producto humano y facilitadoras, en tanto que reproductoras, de la misma praxis, poseen carácter ético. Podemos estar a favor o en contra de una determinada praxis institucional, pero no podemos obviar que ella misma es ethos y que esto implica que la ética compete directamente a tal institución. La ética es un asunto global porque compete a la vida humana entendida globalmente; el análisis de los actos humanos nos muestra la estructuración de los mismos, la respectividad estructural entre individuo y sociedad, entre actividad humana y praxis social, entre sociedad e instituciones. "La humanidad postmoderna requiere nuevos valores, «ideales y concepciones comunes""'2. Es imperativa la tarea de fundar unos valores que respondan a nuestra realidad, y esta realidad no se reduce a lo que es $\longrightarrow$ puede seresta nación. Más que una huida hacia un antes inexistente, más que un rescate de lo que nunca tuvimos -y si lo tuvimos, ahora no nos interesa-, más que un restablecimento, reconocimento de la "vigencia", necesitamos ser creativos críticamente, asumir con responsabilidad el reto de pensar los modos más óptimos de enfrentarnos con las nuevas realidades, que no por ser nuevas significa que sean las mejores, que no porque sean significa que deban.

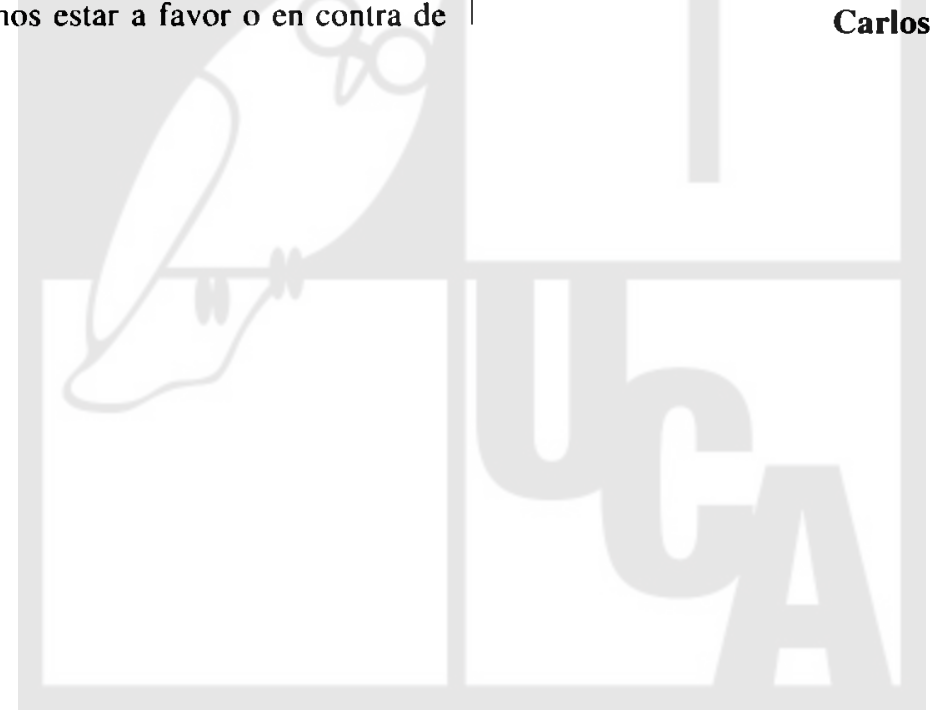

11. Corominas, J. "Hacia una fundamentación mundial de la élica", en Mundialización y liberación. op. cit., p. 256. 12. Silva, E. "Etica, postmodernidad y globalización", en Mundialización y liberación, op. cit., p. 212. 